\title{
FOOD SECURITY STATUS AMONG COCOA GROWING HOUSEHOLDS IN ONDO AND KWARA STATES OF NIGERIA: A DISCRIMINANT ANALYSIS APPROACH
}

\section{Oluyole $\mathrm{KA}^{1}{ }^{*}$}

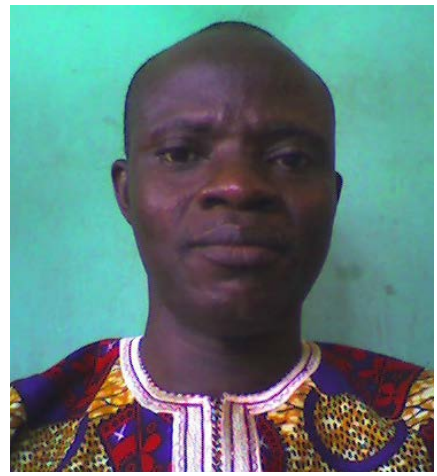

Kayode Oluyole

*Corresponding author email: kayodeoluyole@yahoo.com

${ }^{1}$ Economics Section, Cocoa Research Institute of Nigeria, PMB 5244, Ibadan, Nigeria. 


\section{ABSTRACT}

Cocoa, being a cash crop is mostly cultivated among cocoa farmers without giving much consideration to the cultivation of food crops. There is, however, little evidence on the translation of the income from cocoa production into improved food security by cocoa farmers. This study therefore examined the food security status of cocoa farming households in Nigeria. A simple purposive random sampling technique was used to select 100 cocoa farmers from each of Ondo and Kwara states of Nigeria, thus making a total of 200 respondents used for the study. Information was collected from the respondents with the aid of a structured questionnaire and the data obtained from the information were analysed with Descriptive Statistics, Food Security Index, Surplus/Shortfall Index and Discriminant Analysis. The mean age for the households' head was $53 \pm 16.27$ years while the mean household size was $7 \pm 4.24$ persons per household. The mean per capita food consumption was $2063.15 \pm 1343.55$ kilocalories and the mean monthly farm income was N27,536.50 \pm 29161.74 . With food security line of N1,959.00, $44.0 \%$ of the sampled households in the study area were able to meet the recommended calorie intake of 2450 Kilocalories per capita per day. The food secure households exceeded the calorie requirement by $0.03 \%$ while the food insecure households fell short of the recommended calorie intake by $0.02 \%$. An increase in the value of association membership of household head, off-farm income, farming experience of household head and number of meals taken per day $(p<0.05)$ would improve the food security status of households and hence would shift the households to food security while an increase in the value of household size and per capita non-food expenditure $(\mathrm{p}<0.05)$ would worsen the food security status of households and therefore shift the household to food insecurity. The study recommended that there is a need for an enlightenment programme on birth control and that government can subsidize the price of food items as this will reduce the cost of procuring food items by households thus enabling households to be able to increase the number of meals taken per day. Also, cocoa farming households are encouraged to ensure that income from cocoa is partly used to address food insecurity at household level.

Key words: food security, cocoa farmers, Nigeria 


\section{INTRODUCTION}

Food is a basic necessity of life. Its importance at the household level is obvious since it is a basic means of sustenance [1]. In view of the importance of food in man's life, food is rated as the most basic of all human needs [2]. Man needs food for life's sustenance, prevention of sickness and in providing energy for the normal psychological activities of the body including the normal state of mind [3]. Hence, the need for food security becomes pertinent as it eventually affects a nation's productivity and growth. Food security requires access to food both in terms of availability which is described as the ability of people to access food of adequate nutritional quality and quantity and be able to afford it . In the last decade, attention has been focused on the means to eliminate food insecurity and hunger worldwide. The 1992, International Conference on Nutrition and the 1996 World Food Summit both emphasized the critical need to decrease food insecurity and hunger globally. With increased emphasis on relieving the food crisis and reducing severe consequences of famine and malnutrition on the poor, there is need to carry out more research on food problems in Africa. However, it has been asserted that global or national food security does not necessarily ensure household or individual food security, and that $20 \%-30 \%$ of the population of countries where the per capita supply of food is at or above $100 \%$ of dietary energy needs may persistently subsist on inadequate diets and be unable to meet their requirements for normal physiological functioning, with particularly adverse implications for the nutrition of young children [4]. In many African countries, food security at both the national and household is dismal. Though there are more undernourished individuals in India alone than Africa, it is in Africa that one finds the highest prevalence of undernourishment. Whereas $14 \%$ of the global population is undernourished, $27.4 \%$ of the population of Africa as a whole is undernourished [5]. In some countries, the rate of undernourishment is above $40 \%$ while it exceeds $50 \%$ in those countries experiencing or emerging from armed conflicts [6]. In the West African sub-region, about $16 \%$ of the people are undernourished [2]. The proportion is lower than the regional figure of $27.4 \%$; however, Liberia and Sierra Leone are among those with the highest rate of undernourishment in the continent [7]. In Nigeria, 9\% of the total population was chronically undernourished between 2000 and 2002 [8]. This was less than the regional average of $33 \%$ for Sub-Saharan Africa [2]. However, the $9 \%$ undernourished translate to about $5.4 \%$ of total number of undernourished people in Sub-Saharan Africa as a whole [2].

In Nigeria, the production of food has not increased at the rate that can match the food demand of the increasing population. While food production increases annually at the rate of 2.5 percent, food demand increases annually at a rate of more than 3.5 percent due to the high rate of annual population growth of 2.83 percent [2]. The apparent disparity between the rate of food production and demand for food in Nigeria has led to a food demand-supply gap, leading to a widening gap between the food available and the total food requirement and hence posing a threat to national food security. Although several reports have been published that showed a consistent increase in the production of staple food in the country especially between 1999 and 2005, there is still an observable gap between food demand and food supply [9]. This observable

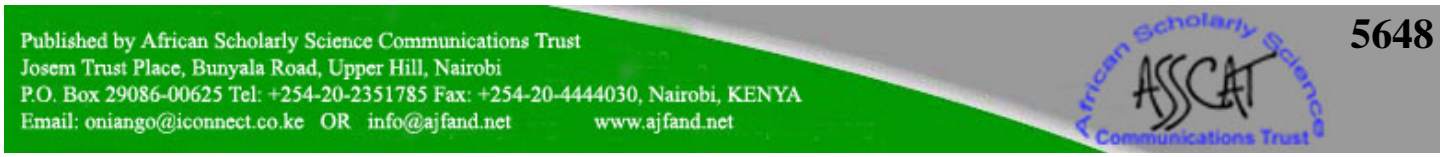


gap is likely to translate into food insecurity. However, some studies had been carried out on the status of food security in Nigeria but none has been carried out on the status of food security among the cocoa farming households in the study area. It is therefore the focus of this study to ascertain the food security status of cocoa farming households in the study area. In Nigeria, Cocoa farming households is a group of individuals whose major occupation is cocoa production and are living together under the same roof and are eating from the same pot or source of provision of food. For household to achieve food security, they must have the means to produce or purchase the food they need to ensure that the dietary requirements of all family members are met.

\section{METHODOLOGY}

The study was carried out in Ondo and Kwara states. Ondo state lies within the Southwestern part of Nigeria. The total area of Ondo state is about 20,595 hectares with a population of about $3,441,024$ people. The state is characterized by heavy rainfall with climate following a tropical pattern. The rainy season is from April to October while the dry season starts from November to March. The state is predominantly an agricultural area and most of the inhabitants (about 70\%) are farmers [10]. The farmers engage primarily in the production of cocoa but often intercrop it with kolanut, oil palm, plantain and banana. Also, food crops like cassava, maize, yam and vegetables are cultivated. On the other hand, Kwara state is in the North-Central zone of Nigeria. The North-Central zone is under the moist savannah agro-ecological zone. The state lies between latitude $7^{\circ} 15^{l}$ and $6^{\circ} 18^{\mathrm{l}}$ of the equator. The state has a humid tropical climate with two seasons; the wet season and dry season. The rainfall ranges between $50.8 \mathrm{~mm}$ during the driest months to $2413.3 \mathrm{~mm}$ in the wettest months. The state is primarily agrarian. The typical cropping system includes food crops (maize, yam, cassava, rice) and cash crops such as cocoa, cashew and oil palm. The data for the study were obtained from a sample survey of cocoa farming households conducted in 2009 in the study area. A random sampling technique was used to select a sample of one hundred cocoa farming households from each of the states (Ondo and Kwara states) making a total of two hundred respondents used for the study. The data collected were analysed with the use of Descriptive Statistics (DS), Food Security Index (FSI), Surplus/Shortfall Index and Discriminant Model.

Descriptive statistics was used to describe the socio-economic characteristics of the respondents and the tools used include frequency and percentage. Food Security Index (FSI) which was generated from the Cost-of-Calorie (COC) function was used to determine the cost of household per capita food consumption. The function is stated thus:

$$
\ln \mathrm{X}=\mathrm{a}+\mathrm{bC}
$$

Where:

$\mathrm{X}=$ Food expenditure $(\mathrm{N})$;

$\mathrm{C}=$ Calorie consumption (Kcal.). 


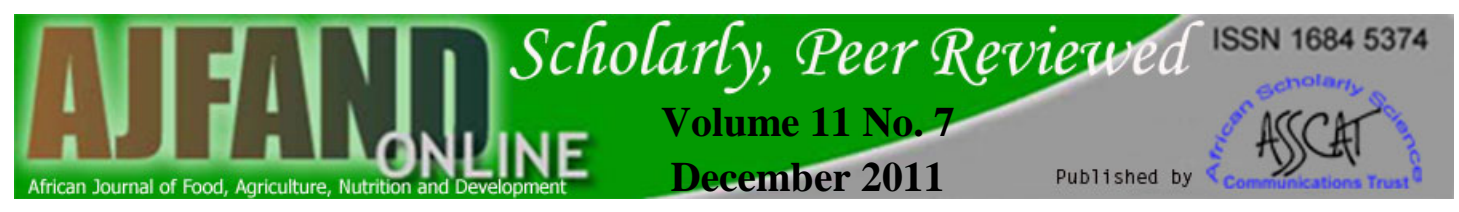

From the COC function, $\mathrm{Z}$ was calculated.

Hence,

$$
Z=e^{(a+b L)}
$$

Where:

$\mathrm{Z}=$ Cost of minimum recommended energy level $(\mathrm{N})$;

$\mathrm{L}=$ Recommended daily energy level (2450kcal.);

$\mathrm{a}=$ Intercept;

$\mathrm{b}=$ Coefficient of the calorie consumption;

$\mathrm{e}=$ A mathematical constant (2.71828).

Any household whose average cost of daily calorie consumption is equal to or more than $\mathrm{Z}$ is said to be food secure while any household with average cost of daily calorie consumption lower than $\mathrm{Z}$ is said to be food insecure.

Surplus/Shortfall Index was used to measure the extent to which a household is food secure or insecure. The index is given as:

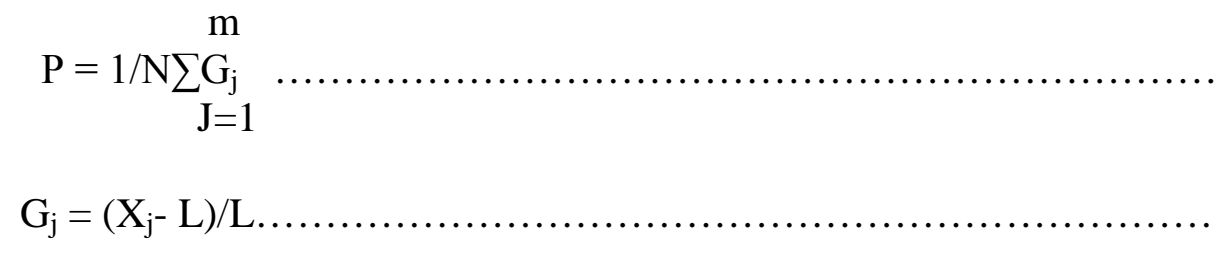

Where:

$\mathrm{P}=$ Surplus/Shortfall Index;

$\mathrm{L}=$ Recommended daily per Capita requirements (2450Kcal.);

$\mathrm{G}_{\mathrm{j}}=$ Calorie deficiency faced by household $\mathrm{j}_{\mathrm{j}}$;

$\mathrm{X}_{\mathrm{j}}=$ Per capita food consumption available to household $\mathrm{j}_{\mathrm{j}}$;

$\mathrm{N}=$ Number of households that are food secure (for Surplus index) or food insecure (for Shortfall index).

The Discriminant Model approach is an effective tool for classifying cases into the value of a categorical dependent, mostly a dichotomy. It is used to investigate differences between groups and discard variables which are little related to group distinction. If the means for a variable is significantly different in different groups, then this variable discriminates between the two groups. This allows the use of that variable to predict group membership [11]. The Discriminant Model used in this study is dichotomous, seeking to discriminate between two groups of households designated as food secure and food insecure. 


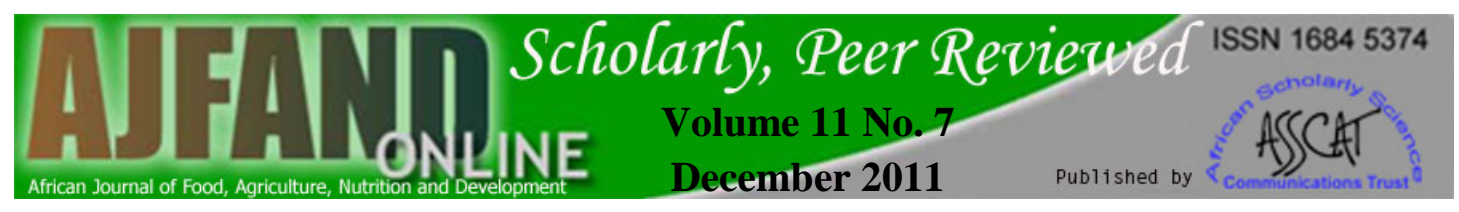

Discriminant Model could be represented as

$$
\mathrm{Z}=\sum \alpha \mathrm{X}+\mathrm{e}_{\mathrm{i}}
$$

Where:

$\mathrm{Z}$ = vector of dependent variable (1 for food secure households; 0 for food insecure households);

$\mathrm{X}=$ vector of explanatory variables (predictors);

$\alpha=$ discriminating coefficients;

$\mathrm{e}_{\mathrm{i}}=$ random error term.

The explanatory variables to be included in the model are:

$\mathrm{X}_{1}=$ Household size (number);

$\mathrm{X}_{2}=$ Gender of household head (1, if male and 0, if female);

$\mathrm{X}_{3}=$ Age of household head (years);

$\mathrm{X}_{4}=$ Educational level of household head $(1=$ No formal education; 2 = Primary education; $3=\quad$ Secondary education; 4 = Tertiary education);

$\mathrm{X}_{5}=$ Marital status of household head (1, if married; 0 , if otherwise);

$\mathrm{X}_{6}=$ Association membership (1, if belongs to association; 0 , if otherwise);

$\mathrm{X}_{7}=$ Farm income $(\mathrm{N})$;

$\mathrm{X}_{8}=$ Off-farm income ( $)$;

$\mathrm{X}_{9}=$ Farming experience of household head (years);

$\mathrm{X}_{10}=$ Household number of meals taken per day (Number);

$\mathrm{X}_{11}=$ Output from roots and tubers $(\mathrm{Kg})$;

$\mathrm{X}_{12}=$ Output from cereals $(\mathrm{Kg})$;

$\mathrm{X}_{13}=$ Output from legumes $(\mathrm{Kg})$;

$\mathrm{X}_{14}=$ Cocoa output $(\mathrm{Kg})$;

$\mathrm{X}_{15}=$ Per capita non-food expenditure ( $\left.\$\right)$;

In discriminant analysis, F-test is used to test if the discriminant model as a whole is significant. Hence, according to [1], a statistical test of significance of the discriminant function requires the computation of a coefficient

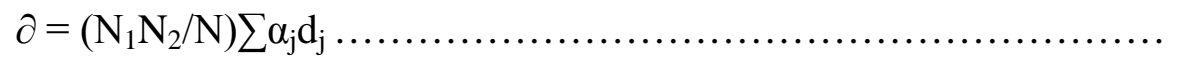

Where: $\mathrm{N}_{1}=$ Number of food secure households;

$\mathrm{N}_{2}=$ Number of food insecure households;

$\mathrm{N}=$ Total number of all the households;

$\alpha_{\mathrm{j}}=$ Discriminating coefficients of variablej;

$\mathrm{d}_{\mathrm{j}}=$ The difference between the mean values of variablej in the two groups (that is food secure and food insecure households).

From equation (vi), F value can be computed

$$
\mathrm{F}=(\mathrm{N}-\mathrm{m}-1) \partial / \mathrm{m}(1-\partial)
$$

$\mathrm{N}-\mathrm{m}-1$ and $\mathrm{m}$ are degrees of freedom.

Where: $\mathrm{N}=$ Total number of all the households;

$\mathrm{m}=$ number of variables investigated;

$\partial=$ The value of the coefficients in equation (iv). 


\section{RESULTS}

1. The mean age of household's head and household size were $53 \pm 16.27$ years and 7 persons respectively.

2. Male headed households constituted 85.0 percent of the respondents.

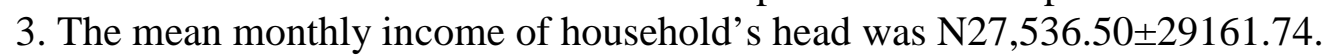

4. The food security line for the study area was N65.35 per day per person (N1959.00 per month). Food security line is the cost of minimum recommended energy level.

5. Forty-four percent of the sampled households were food secure while $56 \%$ of the sampled households were food insecure.

6. The surplus index for the food secure households was 0.03 , while the shortfall index for the food insecure households was 0.02 .

7. The variables that were found to be significant in discriminating between food secure and food insecure households are household size $(\mathrm{p}<0.01)$, gender of household head $(p<0.05)$, association membership of household head $(p<0.01)$, offfarm income $(p<0.01)$, farming experience of household head $(p<0.05)$, number of meals taken per day $(\mathrm{p}<0.1)$ and per capita non-food expenditure $(\mathrm{p}<0.01)$.

\section{DISCUSSION}

Table 1 shows the description of socio-economic and demographic characteristics of the respondents. The table shows that household heads that were 51-60 years of age had the highest proportion, $36.5 \%$ of the total respondents. Meanwhile, the mean age for the households' head was $53 \pm 16.27$ years. About $39.5 \%$ of the total respondent households' head had their age below the mean age, while $58 \%$ of the respondents had their age above the mean age of $53 \pm 16.27$ years. Hence, there were less young households' heads in the study area. This may have negative impact on the farm size since young people are stronger and are expected to cultivate larger farms than older people. It could be observed in Table 1 that male headed households had a higher proportion (85.0\%) of the total respondents than the female headed households. Hence, majority of the households in the study area are headed by males. The dominance of the male over the females may be attributed to the fact that male children are considered as the inheritants of farm land in the study areas. Also, females are involved in off-farm activities such as buying and selling of farm produce, storage of crops and packing of farm produce while their male counterparts were highly involved in tree crop production most especially cocoa in the study area. This is in consonance with [12], who stated that majority of rural women engaged in offfarm activities such as packing of farm produce, buying and selling of farm produce, storage of crops among others. Also cocoa production requires routine management practices that are considered too strenuous for the female to cope with. From the study, 38.5\% had no formal education while $61.5 \%$ had formal education ranging from primary to tertiary education. Hence, most of the households' heads in the study area had formal education. Education is a social capital; hence it could impact positively on household ability to take good and well informed production and nutritional decisions. Therefore education of household head could impact positively on the food security status of household. Majority of the respondent households (72.0\%) had more than four household members. This shows that the substantial

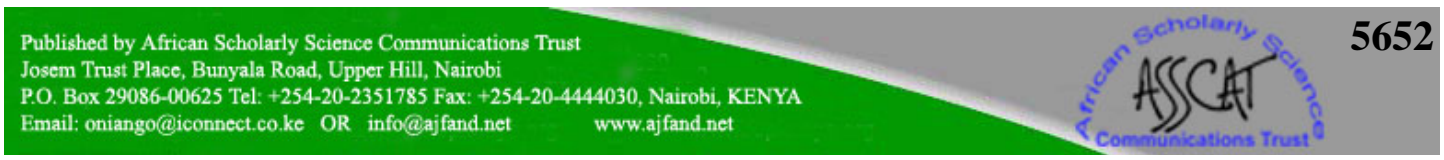


proportion of the households had large household sizes. The household size could have great implications for labour supply, farm work and also food security. A large household is expected to provide more labour for the cultivation of large farm sizes. However, a large household could also be a threat to food security especially when there are many children dependants and elderly people in the household.

Table 3 shows the food security measures of cocoa farming households in the study area. Based on the recommended daily energy levels (L) of 2450Kilocalories [8], the food security line (Z) for the study area was estimated at N65.30 per day per adult equivalent (N1959.00 per month per adult equivalent). On an annual basis, this is equivalent to N23, 508.00 per year per adult equivalent. Results of the analysis showed that the study area could be classified as food insecure, given the fact that only $44.0 \%$ of the sampled households in the study were able to meet the recommended calorie intake of 2450Kilocalories per capita per day, About $56 \%$ of the households were food insecure subsisting on less than the recommended daily per capita calorie requirement of 2450 Kilocalories. The surplus index $(\mathrm{P})$ which measures the extent of deviation by which the food secure households exceeded the calorie requirements was $0.03 \%$, while the shortfall index which measures the extent to which food insecure households fell short of the recommended calorie intake was $0.02 \%$. Head count ratio $(\mathrm{H})$ indicates that $44 \%$ of the individuals in the study area were food secure while $56 \%$ of these individuals were food insecure subsisting on less than the recommended calorie intake of 2450Kilocalories. The low values of both the surplus and shortfall indices shows that the variation of the food secure households and food insecure households from the calorie requirements is minimal.

Table 4 shows the result of the discriminant analysis for the study area. The result shows that out of the fifteen independent variables used in the model, seven variables were found to be significant in discriminating between food secure and food insecure households. The variables are household size $(p<0.01)$, gender of household head $(p<0.05)$, association membership of household head $(p<0.01)$, off-farm income $(p<0.01)$, farming experience of household head $(\mathrm{p}<0.05)$, number of meals taken per day $(\mathrm{p}<0.1)$ and per capita non-food expenditure $(\mathrm{p}<0.01)$. Other variables are insignificant or have weak discriminating factors on the dependent variable. The result is also confirmed by the variables Wilks' Lambda value and F-values. The variables with smaller Wilks' Lambda value and larger F-values are better at discriminating between the food secure and food insecure households in the study area. The sign of the coefficients of these variables shows the direction in which the food security status of a household would move as the values of the variables change. A look at Table 4 shows that the signs of the coefficient of gender of household head, association membership of household head, off-farm income, farming experience of household head and number of meals taken per day are positive. Therefore, an increase in the value of these variables would improve the food security status of a household and hence would shift the household to a food secure group. However, the signs of the coefficients of household size and per capita non-food expenditure are negative. Hence, an increase in the value of the variables would worsen (reduce) the food security status of households and therefore shift the household to a food insecure group [1]. An increase in the household size would shift the household to a food 
insecure group. This is quite obvious because an increase in the number of people in the household means more people are eating from the same resources, hence, the household members may not be able to take enough food when compared to a situation with a smaller household size, thus making the household to be food insecure. This result is in line with the findings of [1] and [13]. The gender of the household head was found to be significant and plays an important role in discriminating between food secure and food insecure households in the study area. Since male is assigned 1, therefore, belonging to household headed by male makes the household to shift to the food secure group. This is because farming being a tedious work, only men will have such strength to cultivate larger farms than their women counterparts. Since the larger the farms cultivated, the more will be the output from the farm and thus making more food available in the household. Association membership of household's head was also found to have an impact on the food security status of households. Hence, any household whose head belongs to an association will shift to the food secure group. This is because belonging to an association may make such a farmer to derive some benefits which will assist him in his farm work. An increase in the value of household off-farm income increases the chances of the household to buy more food for household consumption thus shifting the household to the food secure group. An increase in the years of experience of the household's head shifts the household to the food secure group. This is obvious because an increase in farming experience increases the farmer's efficiency thus enabling the farmer to produce more food. The more the number of meals taken in a household, the more the household shifts to food secure group. This is because an increase in the number of meals taken increases the household per capita calorie consumed thus increases the food security status of the household. An increase in the household's per capita non-food expenditure decreases the food security status of a household thus shifting the household to food insecurity. Spending more money on non-food items decreases the chances of purchasing enough food for household consumption (especially for low and medium income earners). This will have a negative impact on household food security status.

The ranking of the variables on the basis of absolute magnitude of their coefficients was used to infer the relative contribution of the variables to household food security status. In this regard, it was found that household size, number of meals taken per day, farming experience of the household's head, gender of household's head, association membership of household's head, the household per capita non-food expenditure and off-farm income occupy the highest seven ranks in that order in the study area. Hence, this means that household size, number of meals taken per day, farming experience of household's head, gender of household's head, association membership of household's head, household per capita non-food expenditure and off-farm income are the most important variables (in that order) which distinguish food secure households from food insecure households in the study area. 


\section{CONCLUSION AND RECOMMENDATION}

Based on recommended energy level of 2450 kilocalories per person per day and the fact that only $44.0 \%$ of the sampled households were food secure, it could be concluded that the study area is food insecure since a higher proportion (56\%) of the sampled households are food insecure. In line with this, the following recommendations are hereby suggested:

1. There is need to encourage youths to get into cocoa production in the study area. This is quite imperative in as much that only $38.5 \%$ of the respondent farmers were below fifty years of age thus showing that most of the farmers are already aged.

2. The study reveals that food security is significantly affected by household size. This therefore calls for an enlightenment programme on birth control. Hence there should be an enlightenment programme on the populace that they should give birth only to the number of children they could cater for.

3. Government can subsidize the price of food items as this will reduce the cost of procuring food items by households thus enabling households to be able to increase the number of meals taken daily as this significantly affected household food security.

4. Cocoa farming households should be encouraged to ensure that income from cocoa is partly used to address food insecurity at the household level. 


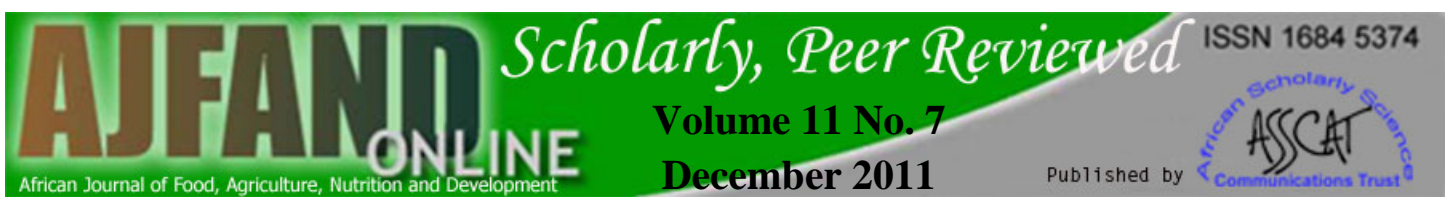

Table 1: Socio-Economic Characteristics of the Respondents

\begin{tabular}{|c|c|c|}
\hline Variable & Frequency & Percentages \\
\hline \multicolumn{3}{|l|}{ Age (years) } \\
\hline$\leq 20$ & 2 & 1.0 \\
\hline $21-30$ & 22 & 11.0 \\
\hline $31-40$ & 37 & 18.5 \\
\hline $41-50$ & 16 & 8.0 \\
\hline $51-60$ & 73 & 36.5 \\
\hline $61-70$ & 24 & 12.0 \\
\hline$>70$ & 26 & 13.0 \\
\hline Total & 200 & 100.0 \\
\hline \multicolumn{3}{|l|}{ Gender } \\
\hline Male & 170 & 85.0 \\
\hline Female & 30 & 15.0 \\
\hline Total & 200 & 100.0 \\
\hline \multicolumn{3}{|l|}{ Educational Status } \\
\hline No formal education & 77 & 38.5 \\
\hline Primary education & 76 & 38.0 \\
\hline Secondary education & 43 & 21.5 \\
\hline Tertiary education & 4 & 2.0 \\
\hline Total & 200 & 100.0 \\
\hline \multicolumn{3}{|l|}{ Marital Status } \\
\hline Single & 2 & 1.0 \\
\hline Married & 193 & 96.5 \\
\hline Widow/widower & 4 & 2.0 \\
\hline Divorced & 1 & 0.5 \\
\hline Total & 200 & 100.0 \\
\hline \multicolumn{3}{|l|}{ Household Size } \\
\hline $1-2$ & 2 & 1.0 \\
\hline $3-4$ & 54 & 27.0 \\
\hline $5-6$ & 61 & 30.5 \\
\hline $7-8$ & 31 & 15.5 \\
\hline 9-10 & 52 & 26.0 \\
\hline Total & 200 & 100.0 \\
\hline
\end{tabular}

Source: Field survey, 2009. 
Table 2: Descriptive Statistics of The Socio-Economic/Demographic Characteristics of the Respondents

Variable

Mean

Standard

Deviation

Age (years)

53

116.27

Household size

7

4.24

Per capita food consumption (Kcal.)

2063.15

1343.50

Cost of per capita food consumption (N) 69.72

49.47

Cost of per capita non-food consumption (N) 71.44

Monthly farm income (N)

$25,536.50$

29161.74

Monthly off-farm income (N)

5950.50

7933.59

Farming experience (years)

28

18.33

Annual food crop production (kg)

$10,599.87$

18.684.58

Annual cocoa production (kg)

969.1

1182.94

Source: Computed from field survey, 2009. 


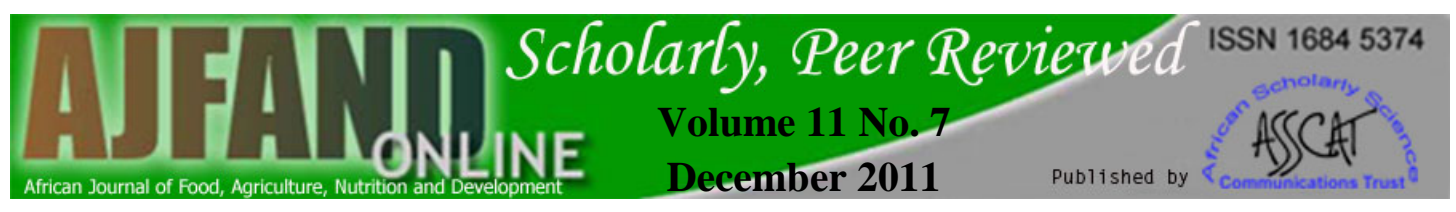

Table 3: Summary statistics and food security indices for the study area

Variables Value

Cost-of-calorie equation $\quad \ln \mathrm{X}=\mathrm{a}+\mathrm{bC}$

Constant

3.3085 (58.92)

Slope coefficient

$0.0003553(15.60)$

Recommended daily energy levels(L) 2450Kcal

Food security line Z: Cost of the

Minimum energy requirements per

Adult equivalent

N65.35 per day

N1959.00 per month

N23,508.00 per year

Head count ratio $(\mathrm{H})$

0.44 (for food secure household)

0.56 (for food insecure households)

Surplus Index

0.03 (for food secure households)

Shortfall Index

0.02 (for food insecure households)

Percentage households

$44.0 \%$ (for food secure households)

$56.0 \%$ (for food insecure households)

Source: Computed from field survey data, 2009

Figures in parentheses are t-values 


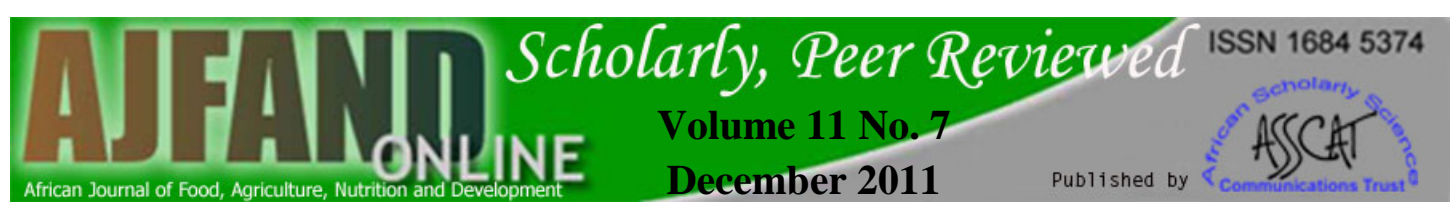

Table 4: Coefficients of discriminant function for the study area.

\begin{tabular}{llll}
\hline Variables & Coefficients & P-values & Rank
\end{tabular}

Household size

$-0.787^{* * *}$

0.000

$1 \mathrm{st}$

Gender of household head

$0.510 * *$

0.033

4th

Age of household head

0.512

0.953

Level of education of household head

0.075

0.223

Marital status of household head

$-0.132$

0.186

Association membership of household head

$0.490 * * *$

0.000

5th

Household farm income

0.066

0.394

Household off-farm income

$0.042^{* * *}$

0.003

7th

Farming experience of household head

$0.582 * *$

0.050

3rd

Number of meals taken per day

$0.625^{* * *}$

0.000

2nd

Output of roots and tubers

1.133

0.828

Output of cereals

0.866

0.481

Output of legume

0.558

0.540

Output of cocoa

0.150

0.217

Per capita non-food expenditure

$-0.341 * * *$

0.000

6th

Wilks Lamda

0.534

Chi-square

11.435

Sig.

0.000

F-value

11.819

Source: Field survey, 2009

*** Significant at $1 \%$, ** significant at $5 \%$ 


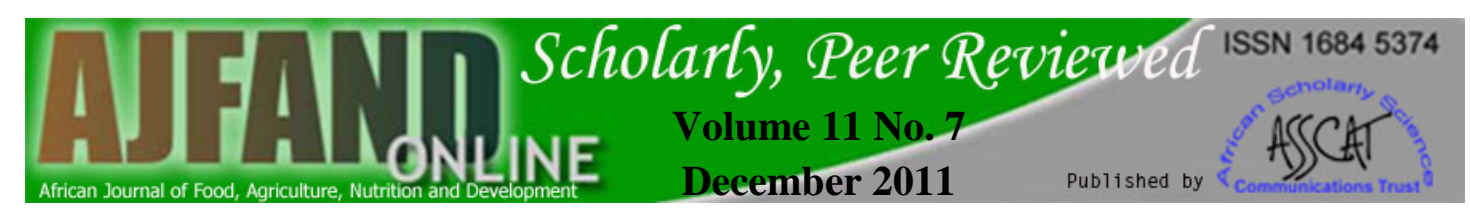

\section{REFERENCES}

1. Olayemi JK Food security in Nigeria. Research Reports No. 2. Development Policy Centre, Ibadan, Nigeria. 1998.

2. Oluyole KA and JO Lawal An Appraisal of the Impact of Agro-services Corporation on Proceedings of the $9^{\text {th }}$ International Conference on Precision Agriculture, 20-23 July, 2008.

3. Adenegan KO and OA Adewusi Determinants of food security status of rural households living with HIV/AIDS in Southwestern Nigeria. African Journal of Biomedical Research. 2007; 10: 9-18.

4. Food and Agriculture Organisation Production Year Book. FAO, Rome, Italy. 1992.

5. Food and Agriculture Organisation The state of food and agriculture, Rome, Italy. 2003.

6. Todd B Africa's food and nutrition security situation, where are we and how did we get there? 2004; IFPRI 2020 discussion paper 37.

7. Babatunde RO, Omotosho OA and OS Sholotan Socio-economic characteristics and food security status of farming households in Kwara State, North-Central, Nigeria. Pakistan Journal of Nutrition. 2007; 6 (1): 49-58.

8. Food and Agriculture Organisation Production year book. FAO, Rome, Italy. 2007.

9. Sanusi RA, Badejo CA and BO Yusuf Measuring household food insecurity in selected Local Government areas of Lagos and Ibadan, Nigeria. Pakistan Journal of Nutrition. 2006; 5: 62-67.

10. Akinsorotan AO Concept of labour pattern among cocoa farmers in Ondo state, Journal of Rural Economics Development. 1997; 13 (1): 85-95.

11. Doppler W Farming and Rural Systems Approaches. Published Lecturing Material. Hohenheim. 2002.

12. Adamu CO, Sodiya CI and JM Awotunde Agricultural Income- Generating Activities of Rural Women in Ijebu North-East Local Government Area of Ogun State. In Proceedings of the Fifteenth Annual Congress of the Nigerian Rural Sociological Association. 2006; 75-76.

13. Obamiro EO, Doppler W and PM Kormawa Pillars of food security in rural areas of Nigeria. 2003; http://www.foodafrica.nri.org (Accessed on 5 August, 2009) 